\title{
PHOTODEGRADATION OF GLYCEROL USING NANOSTRUCTURED TiO CATALYST
}

\author{
E. Coser ${ }^{1,2}$, A. Bervian ${ }^{1}$, S. Khan ${ }^{1}$, A. De León ${ }^{3}$, J. Bussi ${ }^{3}$, S. A. Pianaro ${ }^{2}$, Otto, R. B. ${ }^{4}$, C. Aguzzoli ${ }^{5}$ and C. F. \\ Malfatti $^{1^{*}}$ \\ ${ }^{1}$ Metallurgical Department (DEMET), Pros-graduation Program in Mining Metallurgical and Materials \\ Laboratory of Corrosion Research (LAPEC), Federal University of Rio Grande do Sul (UFRGS) \\ Av. Bento Gonçalves, 9500 Porto Alegre (Brasil) \\ Phone/Fax number:+0051 3308407, e-mail: *celia.malfatti@ufrgs.br, \\ ${ }^{2}$ Department of Materials Engineering (LIMAC), State University of Ponta Grossa (UEPG) \\ Av. Carlos Cavalcanti, 4748 Ponta Grossa (Brasil) \\ ${ }^{3}$ Surface Physical-chemistry Laboratory /DETEMA, Faculty of Chemistry, University of the Republic \\ Av. Gral. Flores, 2124 Montevideo (Uruguay) \\ ${ }^{4}$ Automation and Simulation of Electrical Systems Laboratory (Lasse)- Itaipu Technological Park (PTI) \\ Av. Tancredo Neves, 6731. Foz do Iguaçu - Paraná (Brazil) \\ Phone/Fax number: +55 45 3576.7200, e-mail: rodrigobueno@pti.org.br \\ ${ }^{5}$ Programa de Pós-Graduação em Engenharia e Ciência dos Materiais - PGMAT, Universidade de \\ Caxias do Sul - UCS, Rua Francisco Getúlio Vargas, 1130 - Caxias do Sul, RS, Brazil.
}

\begin{abstract}
The rapid growth in the production of biodiesel and it's primary co-product, i.e. glycerol, has become an environment concern. Currently, several processes have been developed to convert glycerol to other compounds through catalysis. Herein, nanotubular morphology of titanium dioxide $\left(\mathrm{TiO}_{2}\right)$ was obtained by electrochemical anodization and applied in photocatalytic degradation of glycerol. Nanostructured $\mathrm{TiO}_{2}$ catalysts were obtained by anodization in glycerol-ethylene glycol electrolyte containing ammonium fluoride at $60 \mathrm{~V}$ for time durations of 60 and 120 minutes and crystallized through thermal treatment at $450{ }^{\circ} \mathrm{C}$ for $3 \mathrm{~h}$ with a heating ramp of $10{ }^{\circ} \mathrm{C}$ $\mathrm{min}^{-1}$. The samples were characterized by FEG-SEM and XRD. The performances of $\mathrm{TiO}_{2}$ nanotubular photoelectrodes were evaluated via glycerol photodegradation and also for comparison in photo-electrochemical water splitting. The $\mathrm{TiO}_{2}$ nanotubes anodized for 120 minutes presented the best performance in both tests that was related to their optimal morphology and charge transportation.
\end{abstract}

\section{Key words}

Titanium dioxide nanostructures, glycerol photodegradation, photocatalysis

\section{Introduction}

Glycerol $\left(\mathrm{C}_{3} \mathrm{H}_{8} \mathrm{O}_{3}\right)$ is involuntarily produced as a byproduct during the synthesis of biodiesel. In general, about $10 \mathrm{~kg}$ crude glycerol (CG) is produced for every $100 \mathrm{~kg}$ of biodiesel, causing adverse economic and environmental effects. CG glycerol generated by homogeneous base-catalyzed transesterification contains glycerol, organic and inorganic salts, water, soap, alcohol, traces of glycerides and vegetable colour [1],[2]. CG refining to a high purity is too expensive, especially for small and medium biodiesel producers [3]. To improve the economic feasibility of the biodiesel industry, alternate ways of using CG have recently been studied. Possibilities such as combustion, chemical industry, composting, animal feed, thermochemical conversion, and biological conversion have been applied [4].

Heterogeneous photocatalysis is a novel technique with a great potential for the degradation of hazardous organic pollutants, heavy metals removal, inactivation of microorganisms, and also for the water splitting reaction to obtain hydrogen as a clean energy source [5],[6]. In this technique UV-VIS photons are absorbed by a semiconductor, whose band gap energy is equal to or lower than the energy of the photons. The energy of the absorbed photons promotes the passage of electrons from the valence band of the semiconductor to its conduction band. Electrons can reach the surface of the semiconductor and can reduce appropriate species in solution. On the other hand, the holes created in the valence band can also migrate to the surface where they will oxidise available species in solution. In the case of glycerol, its photocatalytic conversion has been studied 
for its degradation into $\mathrm{CO}_{2}$ and $\mathrm{H}_{2} \mathrm{O}$ [7], [8], or to its conversion into more valuable products such as hydrogen [9].

There are various interesting solid materials that can be used as photocatalysts such as $\mathrm{TiO}_{2}, \mathrm{ZnO}, \mathrm{SiC}$ and $\mathrm{CdS}$ etc. Among these photocatalysts the titanium dioxide $\left(\mathrm{TiO}_{2}\right)$ being the most well-known material owing to its high photocatalytic activity, good photostability, nontoxicity, and low price. Because all these advantages, the development of new $\mathrm{TiO}_{2}$ based photocatalysts is explored in order to improve their catalytic properties mainly by increasing their specific surface area and by shifting its optical response to the visible range [10].

Recently, ordered $\mathrm{TiO}_{2}$ architecture has attracted significant attention as a photocatalyst. Of particular interest has been 1-d ordered titanium oxide nanotubes ( $\mathrm{T}$ NT), which have demonstrated interesting optical, catalytic, and electrocatalytic properties for various photorelated applications [11]-[13]. One of the main reasons is the high surface area $\left(1000 \mathrm{~m}^{2} \mathrm{~g}^{-1}\right)$ with electron diffusion higher compared to similar systems based of films made of $\mathrm{TiO}_{2}$ nanoparticles. The synthesis of these T-NT is often carried out by the process of electrochemical anodization of $\mathrm{Ti}$ in fluorinated electrolytes. Highly ordered $\mathrm{TiO}_{2}$ nanotubes arrays with controllable morphologies can thus be obtained [14].

The main organic electrolytes for T-NT production by the anodization process consist of ethylene glycol and glycerol [15]. Ethylene glycol based electrolyte helps for the faster chemical dissolution but the obtained nanotubes sometimes consist of rough walls. On the other hand, glycerol presents higher viscosity that influences the diffusion of ionic species, the kinetics of nanotube formation and its morphology. Therefore it does not show current fluctuations during anodization and hence smooth walled nanotubes are obtained. However, the chemical dissolution of $\mathrm{TiO}_{2}$ in glycerol is slow. Albu et al. [16] and Macak et al. [17] performed the synthesis of different morphologies of $\mathrm{TiO}_{2}$ utilizing either ethylene glycol or glycerol-based electrolytes. However, the use of the mixture of ethylene glycol and glycerol for anodization is not fully developed. Hence it is interesting to use their mixture aiming to obtain efficient nanotubular morphology.

The aim of this work is to obtain $\mathrm{TiO}_{2}$ nanotubes in an electrolyte containing mixture of ethylene glycol and glycerol with different concentrations of fluoride and water to obtain efficient tubular morphology for its applications in glycerol photodegradation. The $\mathrm{TiO}_{2}$ electrodes were used for the glycerol photodegradation employing UVA radiation as light source. For comparison these electrodes were tested in photoelectrochemical water splitting.

\section{Experimental}

Nanotubes were grown on Ti foil grade 2 - ASTMF67 [18], (99.8 - purity: wt. \%, $0.7 \mathrm{~mm}$ thickness, Realum), with dimensions of $1 \mathrm{~cm} \times 5 \mathrm{~cm}$. This foil was cleaned by ultrasonication for $15 \mathrm{~min}$ in degreased and deionized water (DI) in sequence, and then dried under cold air. The Ti foil was used as the working electrode and a platinum foil as the counter electrode. The distance between these electrodes was about $2 \mathrm{~cm}$. The anodization was performed at $60 \mathrm{~V}$ at a potential ramp of $1 \mathrm{Vs}^{-1}$, the organic electrolyte was a mixture of glycerol (Synth 99.5\%) and ethylene glycol (Synth - purity: 99.0\%) in 2:1 $(\mathrm{v} / \mathrm{v})$ ratio and variable amounts of $\mathrm{NH}_{4} \mathrm{~F}$ (Synth - purity: $98.0 \%$ ) and deionized water. Table 1 summarizes the experimental conditions.

Table 1. Experimental conditions for T-NT production by the

\begin{tabular}{cccc}
\multicolumn{4}{c}{ anodization process. } \\
\hline \multirow{2}{*}{ Samples } & $\mathrm{NH}_{4} \mathrm{~F}$ & Deionized water & Anodization \\
& $($ wt. \%) & $($ wt. \%) & time (min) \\
A & 0.25 & 2 & 120 \\
B & 0.75 & 10 & 60 \\
\hline
\end{tabular}

The anodization time (60 minutes and 120minutes) which are described in this work have been studied previously [19] and presented the best photoelectrochemical performance..

After anodization, all the samples were annealed in a muffle furnace at $450{ }^{\circ} \mathrm{C}$ for $3 \mathrm{~h}$ in air with a heating ramp of $10{ }^{\circ} \mathrm{C} \mathrm{min}{ }^{-1}$ to crystallize the $\mathrm{TiO}_{2}$ nanotubes.

\section{Characterization}

The morphology was studied by Field Emission Gun Scanning Electron Microscope (FEG-SEM) equipment MIRA3 by TESCAN operated at 10 and $15 \mathrm{kV}$. The crystal structure was determined by X-ray diffraction (XRD) using XRD 6000 by SHIMADZU, equipped with a graphite mono-chromator and rotating copper anode operated at $40 \mathrm{kV}$ and $30 \mathrm{~mA}$. The X-ray source consisted of $\mathrm{Cu}$ radiation (1.54184 $\AA$ ) selected with a Ni filter. The measurements were performed with a step of $0.04^{\circ}$ and a counting time of $0.60 \mathrm{~s}$ per step.

The photoelectrochemical water splitting measurements were performed using an Autolab potentiostat (PGSTAT 100N). The experiments were performed in a quartz cell using a three-electrode setup employing $\mathrm{TiO}_{2}$ nanotubes as the working electrode, a $\mathrm{Pt}$ 
wire as the counter electrode and $\mathrm{Ag} / \mathrm{AgCl}$ as the reference electrode in aqueous electrolyte of $1 \mathrm{M} \mathrm{KOH}$. The linear sweep voltammetry was performed at a speed of $10 \mathrm{mV} / \mathrm{s}$ in the dark and under illumination. A solar simulator (Newport) incorporated with xenon lamp (Oriel) was used as a radiation source and the radiation was filtered by an AM 1.5G filter. The intensity of the light was calibrated by a photodiode with a known responsivity to $100 \mathrm{~mW} / \mathrm{cm}^{2}$ (i.e. 1 sun illumination).

The photocatalytic activity was evaluated by glycerol photodegradation. The reactor was a tubular quartz cell (10 mm diameter, $120 \mathrm{~mm}$ length) illuminated with three tubular lamps (4x3 watts), which emit UVA light (maximum emission at $360 \mathrm{~nm}$ ). The experiments were performed with two samples placed in the reactor (total anodized surface of $8.1 \mathrm{~cm}^{2}$ ) and $1 \mathrm{mmol} \mathrm{L}^{-1}$ aqueous glycerol solution $(35 \mathrm{~mL})$. The solution was recirculated in the cell bay a peristaltic pump. Aliquots were taken during the test and glycerol concentration was determined by High Pressure Liquid Chromatography (HPLC), using a Shimadzu equipment with refractive index detector.

\section{Results and Discussion}

\section{$X$-ray diffraction $(X R D)$ analysis}

The as-anodized nanotubes are generally amorphous; therefore, thermal treatment is required to crystallize them. Figure 1 shows the XRD patterns of the samples annealed at $450{ }^{\circ} \mathrm{C}$ for $3 \mathrm{~h}$ anodization in different time. The characteristic peak related to the anatase phase of $\mathrm{TiO}_{2}$ appears at $2 \theta=25.2^{\circ}$ i.e. in agreement with the standard JCPDS No.21-1272. The diffractograms of the samples do not present any peak assigned to rutile phase $\left(2 \theta=27 \cdot 36^{\circ}\right)$. Hence, the samples prepared in this work consist of anatase crystalline phase. The peaks at $38.3^{\circ}$, $40.4^{\circ}$ and $53.4^{\circ}$ correspond to $\mathrm{Ti}$ substrate. It should be noted that for long anodization time of 120 minutes the relative intensity of anatase/Ti is higher than that of the sample obtained at short anodization time (60 minutes); hence, thicker oxide film is obtained at 120 minutes of anodization.

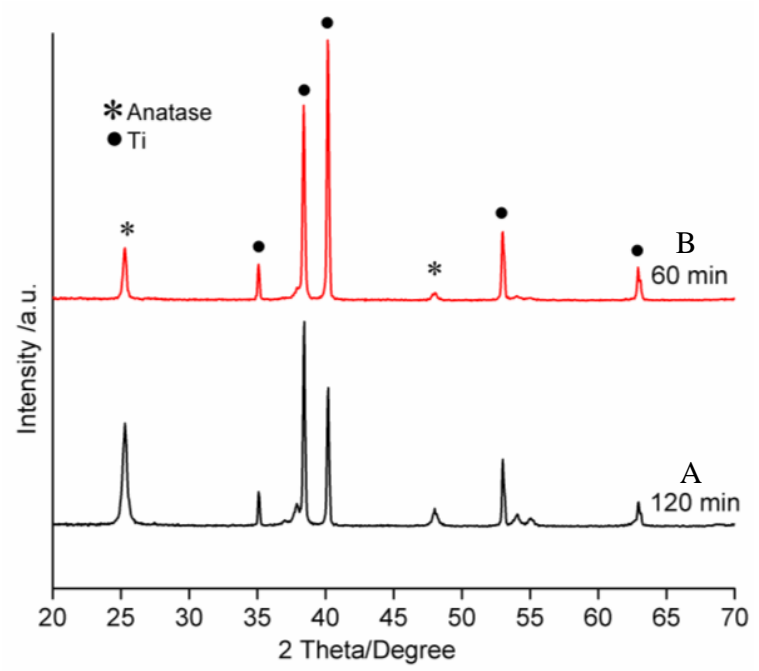

Figure 1: XRD patterns of $\mathrm{TiO}_{2}$ samples annealed at $450{ }^{\circ} \mathrm{C}$ during $3 \mathrm{~h}$, of sample A (120 minutes) and B (60 minutes).

Figure 2 shows the FEG-SEM images of the $\mathrm{TiO}_{2}$ nanotubes that were obtained at different anodization times. The top of the samples can be found covered with debris (according is seen in Figure 2 (a)). It is known that during initial stage of anodization, the penetrated compact oxide, i.e., the random pore layer or the initiation layer, often remains as remnants, and is frequently found in the literature after anodization on the tube tops and is called nanograss [19],[20]. After scratching off the surface of the sample (Figure 2 (a)) a double-walled feature is revealed. The top-view images clearly show that these nanotubes are comprised of inner and outer shells. On the other hand, for sample B Figure 2 (b) (60 minutes anodization) formation of single-walled nanotubes can be observed. The geometric parameters of the nanotubes obtained from the FEG-SEM images are displayed in Table 2.

Table 2: Geometric parameters of $\mathrm{TiO}_{2}$ nanotubes

\begin{tabular}{c|c|c|c|c|c}
\hline Sample & $\begin{array}{c}\text { Length } \\
(\mathrm{nm})\end{array}$ & $\begin{array}{c}\text { Outer } \\
\text { diameter } \\
(\mathrm{nm})\end{array}$ & $\begin{array}{c}\text { Inner } \\
\text { diameter } \\
(\mathrm{nm})\end{array}$ & $\begin{array}{c}\mathrm{FF} \\
(\%)\end{array}$ & $\begin{array}{c}\boldsymbol{\eta} \\
(\%)\end{array}$ \\
A & 2500 & 195 & 49 & 51 & 2.1 \\
B & 700 & 229 & 182 & 44 & 1.8 \\
\hline
\end{tabular}



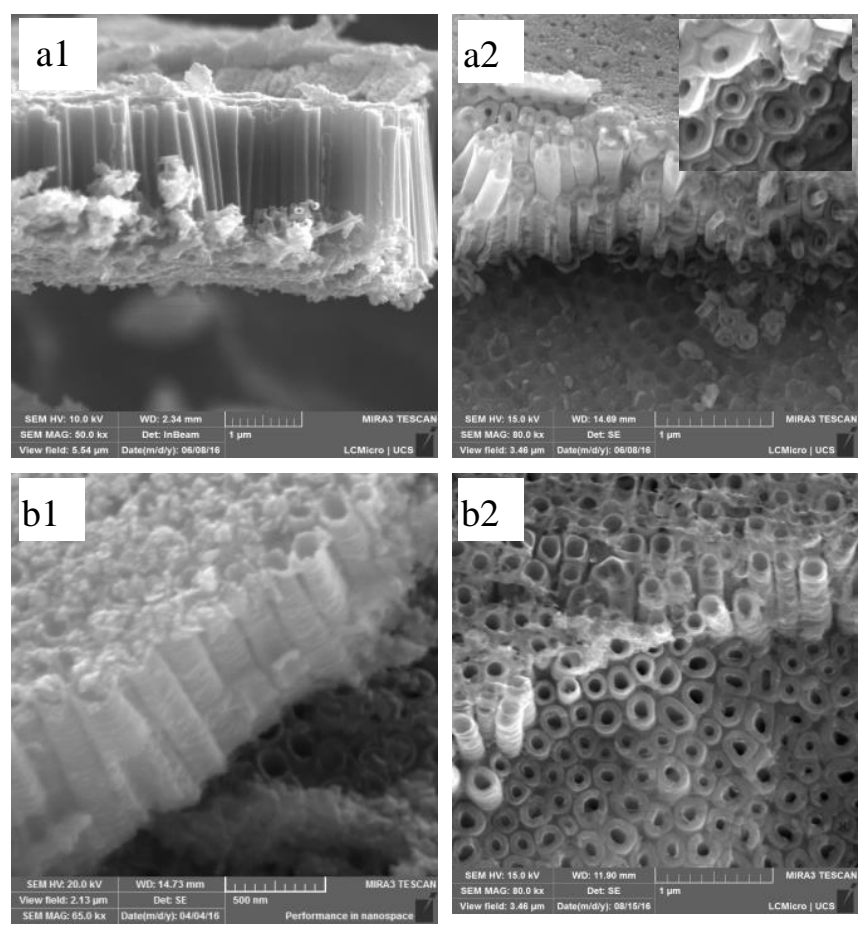

Figure 2: FEG-SEM images coss-sectional and of top of $\mathrm{TiO}_{2}$ nanotubes: (a1 and a2) sample A nanotubes prepared by $0.25 \%$ $\mathrm{NH}_{4} \mathrm{~F}$ in $2 \% \mathrm{H}_{2} \mathrm{O}$ at a potential of $60 \mathrm{~V}$ for 120 minutes and (b1 and b2) sample B nanotubes prepared by $0.75 \% \mathrm{NH}_{4} \mathrm{~F}$ in $10 \%$ $\mathrm{H}_{2} \mathrm{O}$ at a potential of $60 \mathrm{~V}$ for 60 minutes.

Therefore, single-walled or double-walled $\mathrm{TiO}_{2}$ nanotubes can be controllably obtained by optimizing the anodization time. These results indicate the effectiveness of the anodization method in producing well-defined $\mathrm{TiO}_{2}$ nanotubes and controlling the nanotubular morphology via anodization time.

The obtained samples were tested for photoelectrochemical water splitting in $1 \mathrm{M} \mathrm{KOH}$ (aq) electrolyte under AM 1.5 G (1 sun illumination) conditions. The linear sweep voltammetry (LSV) curves are presented in Figure 3. From Figure 3 the values for fill factor (FF) [21] (equation 1) and efficiency $(\boldsymbol{\eta})$ (equation 2) [22] at $0.6 \mathrm{~V}$ vs $\mathrm{Ag} / \mathrm{AgCl}$ for both samples are calculated and are displayed in Table 2.

The equations of the fill factor (FF) (Eqn. 1) and efficiency ( $\boldsymbol{\eta}$ ) (Eqn. 2) can be written in the form:

$$
F F_{1}=\frac{\left(V_{m} I_{m}\right)}{\left(V_{o c} I_{s c}\right)}
$$

Where:

$\mathrm{V}_{\mathrm{m}}=$ Maximum point Voltage;

$\mathrm{I}_{\mathrm{m}}=$ Maximum point Current;

$\mathrm{V}_{\mathrm{oc}}=$ Open Circuit Voltage;

$\mathrm{I}_{\mathrm{sc}}=$ Short Circuit Current.

$$
\eta=\frac{P_{\text {out }}}{P_{\text {in }}} \times 100=\frac{J_{s c V_{o c} F F}}{I_{o}} \times 100
$$

The percentage power conversion efficiency $(\boldsymbol{\eta})$ of any solar cell device is simply the ratio of power output $\left(\mathrm{P}_{\text {out }}\right)$ versus power input $\left(\mathrm{P}_{\mathrm{in}}\right)$, the latter dependent upon the incident light flux $\left(\mathrm{I}_{0}\right)$.

The best photoelectrochemical performance (higher current density) is obtained for sample A (120 minutes of anodization time). This result can be related to the better absorption on longer nanotubes since to ensure efficient electron collection; there should be a balance between the tube length and the optical properties of $\mathrm{TiO}_{2}$ nanotubes. Therefore, 1D nature of $\mathrm{TiO}_{2}$ nanotubes and their optimal light absorption are important factors in improving the photoelectrochemical performance [15].

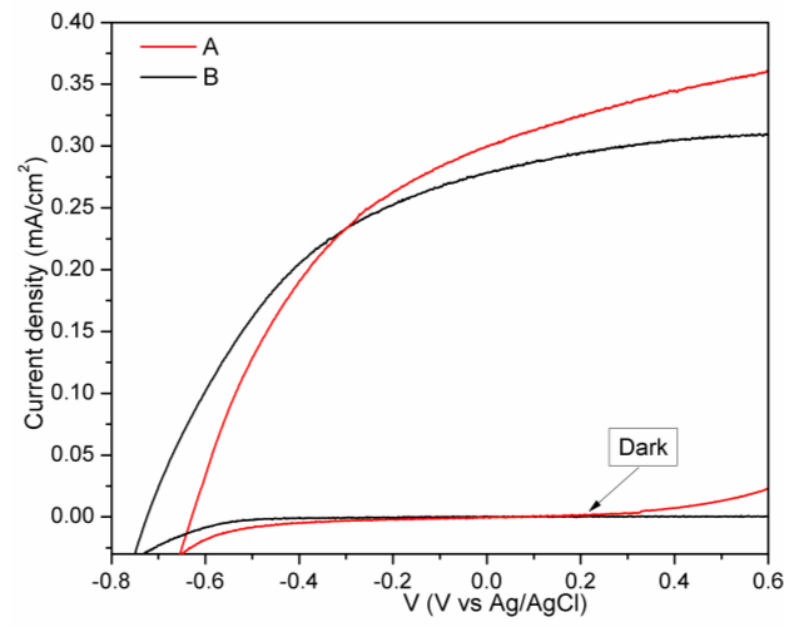

Figure 3: Linear sweep voltammetry curves of $\mathrm{TiO}_{2}$ nanotubes obtained at different anodization times.

Both samples were employed to the photodegradation experiments of the glycerol. The concentrations of glycerol versus time of exposure to ultraviolet radiation are plotted in Figure 4. It is observed that both samples have photocatalytic activity and the process is able to degrade glycerol. Furthermore, the sample A (Figure 4) has achieved a conversion of 52\% after $24 \mathrm{~h}$. However sample B achieved a conversion of $29 \%$ in the same period. These results show that the sample A, which has longer nanotubes and smaller inner and outer diameter (Table 2), has a considerably superior performance compared to the sample B. Thus sample A obtained by anodizing during $120 \mathrm{~min}$ showed the better photocatalytic performance. 


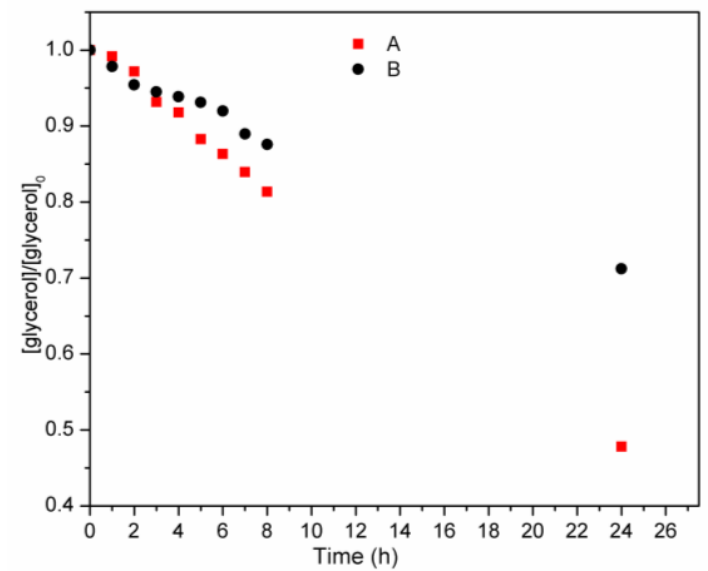

Figure 4: Glycerol photo-degradation results for sample A and sample B tests.

\section{Conclusion}

In summary, it was observed that $\mathrm{TiO}_{2}$ nanotubes obtained in the mixture of ethylene glycol and glycerol consist of well-defined tubular morphology but the top of the nanotubes was covered with nanograss. Doubled wall or single walled topography can be controlled by anodization time and electrolyte composition. For improved photocatalytic performance from the $\mathrm{TiO}_{2}$ nanotubes, the tube length should be sufficiently long to harvest most of the photons, yet short enough to decrease the recombination carriers. The sample prepared for 120 minutes (sample A) has shown improved performances in photocatalytic glycerol degradation with ultraviolet radiation and in water splitting as compared to the other that was obtained in 60 minutes (sample B).

\section{Acknowledgement}

This work was carried out with the support of CAPES, a Brazilian Government entity focused on Human Resources formation. We also thank C-LABMU, UEPG, for carrying out the FEG analysis.

\section{References}

[1] J.C. Thompson, B.B. He. Characterization of crude glycerol from biodiesel production from multiple feedstocks. Applied Engineering in Agriculture 22, (2)(2006), 261-265.

[2] T.Kocsisová, J. Cvengos. G-phase from methyl ester production-splitting and refining. Petroleum and Coal 48 (2006) $1-5$

[3] N. Pachauri, B. He. Value added utilization of crude glycerol from biodiesel production: a survey of current research activities. In Proceedings of the ASABE Annual International Meeting, Portland, Oregon. 9-12 July 2006. American Society of Agricultural and Biological Engineers (ASABE), St. Joseph, Missouri, USA.

[4] C. Santibáñez, M. Teresa Varnero, M. Bustamante. Residual glycerol from biodiesel manufacturing, waste or potential source of bioenergy: a review. Chilean Journal of Agricultural Research 71,(3) (2011) 469-475.

[5] U.I. Gaya, A.H. Abdullah. Heterogeneous photocatalytic degradation of organic contaminants over titanium dioxide:
A review. Advanced research in physics and engineering of fundamentals, progress and problems, Journal of Photochemistry and Photobiology C: Photochemistry Reviews 9 (1)(2008) 1-12.

[6] A. Kudo, Development of photocatalyst materials for water splitting, International Journal of Hydrogen Energy 31(2)(2006), 197-202.

[7] T.S. Yee. Evaluative study of glycerol photocatalytic degradation over $\mathrm{CuFe}_{2} \mathrm{O} 4$ and $\mathrm{La}-\mathrm{CuFe} 2 \mathrm{O} 4$ Photocatalysts. Thesis Faculty of Chemical \& Natural Resources Engineering Universiti Malaysia Pahang (2015).

[8] T. Jedsukontorn, V. Meeyoo, N. Saito, M. Hunsom, Route of glycerol conversion and product generation via $\mathrm{TiO} 2$ induced photocatalytic oxidation in the presence of $\mathrm{H}_{2} \mathrm{O}_{2}$. Chemical Engineering Journal. 281 (2015) 252-264.

[9] V. M. Daskalaki, D.I. Kondarides. Efficient production of hydrogen by photo-induced reforming of glycerol at ambient conditions. Catalysis Today 144 (2009) 75-80.

[10] M. Pelaez, N.T. Nolan, S.C. Pillaib, M. K. Seery, P. Falaras, A.G. Kontos, P.S.M. Dunlop, J.W.J. Hamilton, J.Anthony Byrne, K. O'Shea, M.H. Entezari, D.D. Dionysiou. A review on the visible light active titanium dioxide photocatalysts for environmental applications. Applied Catalysis B: Environmental 125 (2012) 331-349.

[11] J. Dong, J. Han, Y. Liu, A. Nakajima, S. Matsushita, S. Wei, W. Gao, Defective Black TiO2 Synthesized via Anodization for Visible-Light Photocatalysis, ACS Appl. Mater. Interfaces. 6 (2014) 1385-1388.

[12] Y. Dongliang, Y. Song, X. Zhu, R. Yang, A. Han, Morphological evolution of $\mathrm{TiO} 2$ nanotube arrays with lotus-root-shaped nanostructure, Appl. Surf. Sci. 276 (2013) 711-716.

[13] R.P. Lynch, A. Ghicov, P. Schmuki, A PhotoElectrochemical Investigation of Self-Organized $\mathrm{TiO} 2$ Nanotubes, J. Electrochem. Soc. 157 (2010) G76-G84.

[14] Z.B. Xie, D.J. Blackwood. Effects of anodization parameters on the formation of titania nanotubes in ethylene glycol. Electrochimica Acta 56 (2010) 905-912.

[15] I. Roman, R.D. Trusca, M.-L. Soare, C. Fratila, E. Krasicka-Cydzik, M.-S. Stan, Titanium dioxide nanotube films Preparation, characterization and electrochemical biosensitivity towards alkaline phosphatase Mater. Materials Science and Engineering C, 37 (2014) 374-382.

[16] S.P Albu., A. Ghicov, et al. Formation of Double-Walled $\mathrm{TiO}_{2}$ Nanotubes and Robust Anatase Membranes. Adv. Mater. 20, (2008), 4135.

[17] J.M. Macak, H. Tsuchiya, et. al., TiO2 nanotubes: Selforganized electrochemical formation, properties and applications. Curr. Opin. Solid State Mater. Sci. 11, (2007), 3-18.

[18] ASTM - F67-13, Standard Specification for Unalloyed Titanium, for Surgical Implant Applications (UNS R50250, UNS R50400, UNS R50550, UNS R50700).

[19] A. Bervian, E. Coser; et al. Evolution of TiO2 Nanotubular Morphology in Ethylene Glycol Mixed with Glycerol Electrolyte and its Photoelectrochemical Performance. The Canadian Journal of Chemical Engineering. (2016) 1-15.

[20] S. So, I. Hwang, P. Schmuki, Hierarchical DSSC structures based on "single walled" $\mathrm{TiO} 2$ nanotube arrays reach a back-side illumination solar light conversion efficiency of 8\%. Energy Environ. Sci. 8 (2015) 84-854.

[21] R. Guliani, A. Jain and A. Kapoor. Exact Analytical Analysis of Dye-Sensitized Solar Cell: Improved Method and Comparative Study. The Open Renewable Energy Journal, 5 (2012) 49-60.

[22] J. Rochford, CH 371 - Advanced Inorganic Chemistry Laboratory, Spring 2013, part Power Conversion Efficiency of a Dye-Sensitized Solar Cell. Accordance with site http://alpha.chem.umb.edu/chemistry/ch371/ 